\title{
GENDER AND TRANSPORT: WOMEN'S PROCLIVITY TO MINIMIZE CAR USE IN AKURE, NIGERIA
}

\author{
E. Okoko \\ Department of Urban and Regional Planning \\ School of Environmental Technology \\ Federal University of Technology \\ P.M.B 704, Akure, Ondo State, Nigeria.
}

\begin{abstract}
The sustainability of the physical environment has now attracted the attention of various professionals, not least, transportation planners. It is incontrovertible that motorcars contribute, in no small measure, to environmental greenhouse gases. In contemporary times, there has been a clarion call from experts to car owners, stressing the need to reduce car trips. Evidences from existing literature tend to suggest that women are more likely to heed this call than men. This article therefore explores the propensity of female car owners in Akure to reduce their car trips and patronize public transport. Using a non-probability sampling technique, 100 female drivers, who normally drive in their cars to work, were sampled from Akure urban traffic for this study. Some probabilistic models were employed to classify the sampled respondents into their appropriate mode - choice category. The model predicted an increase in the number of women who preferred to discard their private cars for a public transport mode in Akure. The paper concludes with recommendations on ways of encouraging female car-owners to patronize public transport mode in their journey to work in Akure.
\end{abstract}

Keywords: gender, transport, women, proclivity, car, Akure, Nigeria.

\section{INTRODUCTION}

The issue of gender and transportation has, in recent years, attracted the attention of transportation planners. This nascent interest stems from the pioneering works of Rosenbloom (1978) and Guiliano (1979). Their path-breaking articles laid the groundwork for a body of research, which rejected the neuter commuter assumption and began to distinguish women's pattern of mobility in the urban space from those of men (Law, 1999).

The Earth Summit that was held in Rio de Janeiro, Brazil, in 1992, brought to the fore the need for global environmental sustainability. One of the strategies that were put forward to achieve the goals of sustainable environment was a common agreement by all the participating countries to reduce greenhouse gas emissions

150 Journal of Science and Technology, Volume 27 no. 2, August, 2007 
into the atmosphere. The emission of greenhouse gases into the atmosphere has led to the depletion of the ozone layer, and this in turn, has contributed significantly to global warming. The major source of these greenhouse gases in the urban areas is the combustion of fossil fuels by automobiles.

Transportation planners have argued persistently that there is need for the reduction of car use by city dwellers. This call is predicated on the understanding that if the concept of sustainable environment is going to be achieved, the rate of emission of Carbon Dioxide $\left(\mathrm{CO}_{2}\right)$ and Carbon Monoxide $(\mathrm{CO})$ gases into the atmosphere must be curtailed. Transportation is a major user of combustion fuel. Motorcars, by virtue of their large numbers in urban areas, contribute to the high concentration of greenhouse gases in the atmosphere.

The role of private cars in causing global environmental pollution has been highlighted by Hughes (1993) and Whitelegg (1993). The economic cost of using private cars over public transport has been discussed by Peirson et al (1996) and Maddison et al (1996). Private cars are less efficient in bulk carriage of passengers and goods compared to public transport. Moreover, in a situation where we have a preponderance of private cars, efficient traffic management machinery must be put in place to forestall traffic congestion and incessant cases of road accidents.

Ullrich (1990) in a study he carried out in Germany discovered that most intra-urban journeys were of a short duration of about 5 minutes. The implication of this is that most private cars operate inefficiently in terms of energy consumption. On short-distance journeys, the car engine is cold and runs least efficiently. The implications of driving a cold engine on urban roads in urban traffic conditions have been pointed out by Potter and Hughes (1990). Consequently, there is an advocacy by urban transport experts to imbibe policies that will reduce car use e.g. car pooling, cycling and public transport (Tolley, 1997; Atash, 1994; Cervero and Radisch, 1996).
In recent years, there has been a noticeable ascendancy in the number of private cars on urban roads in Akure. This assertion is attested to by the car registration records of the Vehicle $\mathrm{Li}$ censing Department in Akure town. The high population of cars on urban roads often leads to accidents and the formation of long platoons of cars at road intersections during rush hours. The economic implication of wasted man-hours arising from accidents and traffic queue in Nigeria has been investigated by Arosanyin (2000). In some cases, the journeys undertaken by car owners in their private cars are of short distances or short duration. Such short journeys should normally be undertaken using public transportation modes.

Women are the focus of this research because there is ample evidence in the literature to suggest that women are more willing than men to use public transport, independent of their actual car access. It has been shown that women have weaker car habits and stronger obligation to reduce car use in favour of public transport (Matthies, et al, 2002; Kaiser, 1998). Hanson and Hanson (1980) noted that women travel less frequently than men, and they travel shorter distances than men do, and rely on bus (public transport) to a greater extent than men.

\section{Theoretical and Analytical Undertones}

It is now certain that there is a remarkable difference in the mode-choice behaviour of men and women. Matalon (1982) observed that the travel behaviour of individuals is not uniform and he attributed this difference in travel behaviour of individuals to their sex (gender). The difference in the travel behaviour of men and women stems from the fact that women are vulnerable to a number of factors in their choice of travel mode or in their travel behaviour. Such factors include their attachment and affinity to the environment, cultural norms, their traditional sex roles, societal vices and all such-like factors. Men perceive these factors differently and they therefore play a minimal role in their mode-choice behaviour. Fadare and Morenikeji (2001), for example, stud- 
ied the gender bias in intra-urban trip pattern in Niger state, Nigeria and concluded that there was a remarkable difference in the travel behaviour of men and women.

Studies all over the world tend to give credence to the fact that there is a gendered dissimilarity in the mode choice behaviour of men and women (Asensio, 2002; Dieleman, et al 2002). For example, studies in Germany, Switzerland and Austria have shown that women use public transport more than men and reversibly use cars less frequently (Matthies et al, 2002). Evidences also abound to sustain the assertion that there is gender bias in the mode-choice behaviour of commuters, e.g. in the mode of travel to work (Falade, 1989). One explanation for the modechoice behaviour of women is derived from the concept of ecofeminism. According to this concept, women are more concerned about the environment than men and consequently, they feel a stronger obligation to behave in an environmentally friendly way. It has been reported that health and safety are more salient to women, and they therefore have higher levels of concern than men with regards to a given level of environmental pollution (Davidson and Freudenburg, 1996, Matthies, 2002).

Habit has also been identified as a factor that has a manifest influence on women's ecological travel behaviour. Verplanken et al (1994) stated that traveling has in many cases a strong repetitive character e.g. making exactly the same journey to work under the same circumstances in the same way every morning. They therefore opined that traveling in such situations is not guided by deliberate decisions, but is habitual. The concept of habit thus accounts for the fact that current baviour has its roots in former behavioural experiences (Ouellette and Wood, 1998). In the context of travel mode choice, this means that individuals who frequently travel by car in similar situations may develop a stronger car habit than individuals who travel less often or in changing contexts (e.g. sometimes by car, and sometimes by public transport).
The logit and discriminant models are more often than not employed in the analysis of modal split or mode-choice behaviour of commuters. Human behaviour is generally seen as a product of chance decisions governed by random variables that are not usually amenable to deterministic modelling. Consequently, human actions and behaviour are typically analyzed using probabilistic or stochastic models. The multinomial or binary logit models and the discriminant model are typical probabilistic models that have found wide application in modal split analysis.

The propensity to discard a private car for a public transport mode is a transportation version of decision making involving a choice of a mode vis $a$ vis other alternatives. Consequently, a modal choice or modal split model is concerned with the trip makers' behaviour regarding the selection of travel mode. Modal split modelling is thus the transportation adaptation of the general model of human choice that explains how people select between competing alternatives (Kanafani, 1983).

The multinomial (polychotomous) and binary (dichotomous) logit models are widely used in analyzing modal choice pattern. This model seeks to determine the proportion of trips that will select a specific mode (say mode $\mathrm{k}$ or i) according to the following equations, which involve the exponential transformation of the utilities (Papacostas, 1987).

$\mathrm{p}(\mathrm{k})=\frac{\mathrm{e}^{\mathrm{uk}}}{\sum_{x=1}^{n} e^{u x}}=\frac{2.7183^{\mathrm{f}(\mathrm{x})=\mathrm{a}+\sum_{j=1}^{\mathrm{n}} \mathrm{b}_{\mathrm{x}} x_{i}}}{\sum_{x=1}^{n} 2.7183^{\mathrm{f}(\mathrm{x})=\mathrm{a}+\sum_{i=1}^{\mathrm{n}} \mathrm{b}_{i} x_{j}}}$

where, $\mathrm{p}(\mathrm{k})=$ the proportion of trips going to mode $\mathrm{k}, \mathrm{u}^{\mathrm{k}}=$ the utility of mode $\mathrm{k}$;

$\mathrm{u}^{\mathrm{x}}=$ the utility of all the competing or alternative modes, e $=2.7183$.

In the dichotomous or binary logit model, only two competing modes are involved, and the model is given as:

152 Journal of Science and Technology, Volume 27 no. 2, August, 2007 


$$
\mathrm{p}(\mathrm{k})=\frac{\mathrm{e}^{\mathrm{uk}}}{1+e^{u x}}=\frac{2.7183^{f(x)}}{1+2.7183^{f(x)}}
$$

In logit modeling, if the probability of choosing mode (k) is as given in equation (2), then the probability of the alternative mode could be stated as:

$$
1-\mathrm{P}(\mathrm{k})=\frac{1}{1+\mathrm{e}^{\mathrm{ux}}}
$$

These logit models are non-linear because they contain exponential functions. To use a linear logit model to make predictions about the travel behaviour of commuters, the non-linear logit model has to be transformed to a linear logit model. The transformation follows the modus operandi set out by Wrigley (1981), i.e.

$$
\frac{\mathrm{P}(\mathrm{k})}{1-\mathrm{P}(\mathrm{k})}=\mathrm{e}^{\mathrm{a}+\sum_{\mathrm{i}=1}^{\mathrm{n}} \text { bixi }}
$$

It is common modeling knowledge that if $y=e^{x}$, then $\mathrm{x}=\log _{\mathrm{e}} \mathrm{y}$, therefore,

$$
\log \frac{P(k)}{1-P(k)}=a+\sum_{i=1}^{n} b_{i} x_{i}
$$

The left hand side of equation (5) is the log transformation of $\mathrm{P}(\mathrm{k})$, otherwise called logit transformation ( $\mathrm{Li})$. Thus $\mathrm{Li}$ is:

$$
\mathrm{Li}=\log _{\mathrm{e}} \frac{\mathrm{P}(\mathrm{k})}{1-\mathrm{P}(\mathrm{k})}
$$

We can substitute equation (6) into equation (5) to have the linear logit model for the commuter who will use mode $(\mathrm{k})$ i.e.

$$
\mathrm{Li}=\mathrm{a}+\sum_{\mathrm{i}=1}^{\mathrm{n}} \mathrm{b}_{\mathrm{i}} x_{i}
$$

The discriminant analysis on the other hand, explains how individuals make a choice of modes in the face of competing alternative modes of city transport. It makes it possible to classify members of a population into their appropriate groups using a set of independent variables. In practical terms, we can use discriminant analysis to analyse a number of variables and use the result to determine members of a given population that should be allocated to some pre-determined sub-groups. For example, we can use discriminant analysis to allocate commuters to say, private mode or public mode of intracity transport.

The discriminant function, $\perp$, serves as a cut-off point for allocating commuters to their proper modes of transport. The discriminant function is calculated from a linear combination of some variables and the resultant coefficients are usually presented in standardized form (equation 8), though it is also possible to present the coefficients in unstandardized forms.

$$
\perp=\sum_{i=1}^{n} \beta_{i} X_{\mathrm{i}}
$$

where,$I=$ the discriminant function; $\beta_{\mathrm{i}}=$ Standardized betta coefficients; $X_{i}=$ the discriminating variables.

\section{The Study Methods}

The study area for this research is Akure, the capital city of Ondo State in Nigeria. According to the 1991 National census, the population of Akure was given as 239,124, and a projected population of 517,238 in 2006. Akure is unarguably the most populous town in Ondo State. Data for this study came from a sample of 100 female car owners drawn from different socioeconomic sectors/neighbourhoods in Akure town. The choice of this moderate sample size was influenced by the fact that some female car owners were suspicious and un-cooperative during the research. However, a sample size of 100 is generally regarded as a large sample in social research (Bailey, 1982) and is therefore amena- 
ble to valid conclusions and generalizations. A non-probability sampling technique called purposive or judgemental sampling was adopted for this study. In purposive or judgemental sampling, the researcher relies on his judgment about which respondents to choose, and picks only those who best meet the purpose of the study. This was necessary because some of the respondents had to be contacted in their places of work, some at home and others were selected from the urban traffic.

The readiness of female derivers to reduce car use was investigated in this study using the logit model and the discriminant analysis discussed above. The binary or dichotomous logit model was used to determine the conditional probability that the $\mathrm{i}^{\text {th }}$ female driver in the urban traffic will park her private car at home and use public transport for the next journey to work. The binary logit model was used because the criterion variable was measured on a binary scale. A scientific classification of female drivers in the urban traffic into two classes (i.e. those that are truly willing to abandon their cars for public transport and those that are not) was done using the discriminant analysis.

In order to achieve the object of this research, one dependent variable (Y) and eight independent variables $\left(\mathrm{X}_{1}-\mathrm{X}_{8}\right)$ were fed into these probabilistic models. These variables are:

$\mathrm{Y}=\quad$ willingness to use public transport for subsequent work trips;

$\mathrm{X}_{1}=$ access to private car; $\mathrm{X}_{2}=$ number of cars in the family;

$\mathrm{X}_{3}=$ Perception of car use as a pollutant;

$\mathrm{X}_{4}=$ Perception of car use as an agent of traffic congestion;

$\mathrm{X}_{5}=$ Perception of car use as a status symbol;

$\mathrm{X}_{6}=$ Travel time involved in work trip;

$\mathrm{X}_{7}=$ Academic attainment of the female driver;

$\mathrm{X}_{8}=$ Perception of public transport service in Akure.

\section{RESULTS AND DISCUSSION \\ Binary Logit Modelling:}

The dichotomous or binary logit model was used in this analysis because the criterion variable in the model was measured on a binary (dummy or dichotomous) scale. The modal choice logit model provides an explanation for the conditional probabilities of a female driver or car owner using a public transport mode instead of her private car. The model has the same structural form as equation (2) and is given as:

$$
\mathrm{P}(\mathrm{i})=\frac{\mathrm{e}^{\mathrm{uk}}}{1+e^{u x}}=\frac{e^{f(x)}}{1+e^{f(k)}}=\frac{2.7183^{f(x)}}{1+2.7183^{f(x)}}
$$

note: e is equal to 2.7183 , and $\mathrm{p}(\mathrm{i})$ (or $\mathrm{p}(\mathrm{k})$ is the probability of selecting a particular mode, notionally denoted by (k) or (i), depending on the discretion, whims and caprices of the researcher.

Where: $\mathrm{P}(\mathrm{i})=$ the probability that a female commuter will prefer a public mode to a private mode; $f(x)=$ a linear combination of various parameters; $\mathrm{e}=\mathrm{a}$ Napierian constant representing the coefficient of modal choice explanation.

In order to meet the objective of this study, equation (9) had to be presented in form of the logs of the odds of choosing one alternative mode of transport over the other, i.e.

$\operatorname{Logit} \mathrm{P}(\mathrm{i})=\log _{\mathrm{e}} \frac{P(i)}{1-P(i)}=f(x)$

Equation (10) is the logistic regression model and can conveniently be represented as:

Logit $\mathrm{P}(\mathrm{i})=\mathrm{f}(\mathrm{x})=\mathrm{a}+\sum_{\mathrm{i}=1}^{\mathrm{n}} \mathrm{b}_{\mathrm{i}} x_{i}$

The probability that a female driver will choose a public mode $\mathrm{i}[(\mathrm{P}(\mathrm{i})]$ in this study was determined using equation (12) i.e.

$\mathrm{P}(\mathrm{i})=\frac{\exp (\log i t P(i)}{1+\exp (\log i t P(i)}$

The variables that were used to calibrate the modal choice model included the dependent (criterion) variable and the predictor variables

154 Journal of Science and Technology, Volume 27 no. 2, August, 2007 
listed above. The forced entry technique of model calibration was employed and all the variables were therefore accommodated in the model. The model achieved convergence after thirteen (13) iterations and the log odds or logit coefficients of the variables based on equations (11) and (12) are shown in equations (13) and (14) respectively.

$$
\begin{aligned}
\text { Logit } \mathrm{P}(\mathrm{i})= & 42.889+\left(-3.454 \mathrm{X}_{1}\right)+\left(-.606 \mathrm{X}_{2}\right)+\left(-1.658 \mathrm{X}_{3}\right)+1.578 \mathrm{X}_{4}+0.387 \mathrm{X}_{5} \\
& +\left(-4.03 \mathrm{X}_{6}\right)+1.314 \mathrm{X}_{7}+0.420 \mathrm{X}_{8}
\end{aligned}
$$

and

$\mathrm{P}(\mathrm{i})=\frac{2.7183^{42.889+\left(-3.454 \mathrm{X}_{1}\right)+\left(-\ldots 606 \mathrm{X}_{2}\right)+\left(-1.658 X_{3}\right)+\left(1.578 X_{4} .+0.387 X_{5}+\left(-4.03 x_{6}\right)+1.314 X_{7}+0.420 X_{8}\right.}}{1+2.7183^{42.889+\left(-3.454 \mathrm{X}_{1}\right)+\left(-.606 \mathrm{X}_{2}\right)+\left(-1.658 \mathrm{X}_{3}\right)+1.578 \mathrm{X}_{4}+0.387 \mathrm{X}_{5}+\left(-4.03 \mathrm{X}_{6}\right)+1.314 \mathrm{X}_{7}+0.420 \mathrm{X}_{8}}}$

The negative log likelihood (- In (likelihood) associated with the calibration of the logit model of equation (14) is -19.806 . This is a measure of the consistency between the data and the logit model. It represents the probability that the data will produce a good logit model. The probability is usually very large but less than 1 . Thus the natural logarithm of likelihood values is taken, and since the probability is less than 1 , the logs are always negative. The negative log likelihood value of -19.806 suggests a good fit between the logit model and the raw data.

The conditional probability of a female driver in Akure selecting a public mode of transport [P(i)] for her trip is given in equation (14). Since the model output of equation (14) is in form of probabilities, the model output must, of necessity, yield probability values of between 0.0 and 1.0. Actual values could be substituted into equation (14) to obtain probability values and predictions on the probability of the $i^{\text {th }}$ female driver in Akure choosing a public transport mode instead of her private car.

Equation (13) could be used on its own to make predictions as well concerning the mode choice behaviour of female drivers in Akure town. It gives information on the specific effect of each of the variables on the propensity of a female driver in Akure to discard her private car for a public transport mode. For example, it is possible to use equation (13) to determine the cut-off travel time i.e. the travel time at which the $i^{\text {th }}$ female driver has an equal chance or probability of using either her private car or public transport i.e $\mathrm{P}(\mathrm{i})=0.5$ or $50 \%$.

In order to confirm the reliability of these coefficients, the model was subjected to a number of tests. The validity of the coefficients and the negative log likelihood was tested using the chisquare test and the coefficients were found to be significant at $1 \%$ critical limit. The predictability of the model was measured using the Cox and Snell R square test and the coefficients of determination was as high as $69 \%\left(\mathrm{R}^{2}=.6910\right)$. The next test that was conducted was the Negelkerke $\mathrm{R}$ - square test and the proportion of the variance of the dependent variable that was accounted for by the joint variance of the predictor variables was as high as $92 \%\left(\mathrm{R}^{2}=0.926\right)($ Table 1.0)

Ultimately, the logit model re-classified female commuters based on the logit log odds or coefficients into their proper modal choice groups. Out of 56 female drivers who preferred the private mode of transport, the model predicted that it is actually 53 of them who should have opted for the private mode. The model further predicted that out of the 44 empirical female drivers who were prepared to discard their cars for a public mode, it is actually 47 of them that should really do that (Table 2). The overall percentage of the cases that was correctly predicted is $95 \%$. 
Table 1: Omnibus tests of model coefficients

\begin{tabular}{cccccc}
\hline -Log likelihood & Chi-square & $\begin{array}{c}\text { Degree of } \\
\text { freedom }\end{array}$ & $\begin{array}{c}\text { Cox and } \\
\text { Snell } \mathbf{R}^{\mathbf{2}}\end{array}$ & $\begin{array}{c}\text { Negelkerke } \\
\mathbf{R}^{\mathbf{2}}\end{array}$ & Sig. \\
\hline 19.806 & 117.380 & 8 & .691 & .926 & .000 \\
\hline
\end{tabular}

Table 2: Logit model classification table

\begin{tabular}{lccc}
\hline Observed & $\begin{array}{c}\text { Private } \\
\text { mode }\end{array}$ & $\begin{array}{c}\text { Public } \\
\text { mode }\end{array}$ & $\begin{array}{c}\text { Percentage } \\
\text { correct }\end{array}$ \\
\hline Private mode & 52 & $4(0)$ & 92.9 \\
Public mode & $(56) 1$ & $43(44)$ & 97.7 \\
$\begin{array}{l}\text { Overall } \\
\text { percentage }\end{array}$ & & & 95.0 \\
\hline
\end{tabular}

Note: actual values are in parenthesis

\section{Discriminant Analysis}

The discriminant analysis was used in this study to classify female drivers into their appropriate mode-choice group based on a set of discriminating variables. This classification relied on the computed discrimnant function and the discriminant score for each of the female drivers in the sample. The dependent (criterion) variable and the discriminating variables are the same as those that were employed in the binary logit modelling above.
The discriminant functions were derived using two different techniques. The first is the canonical discriminant function and the associated coefficients and the second is the Fisher's linear discriminant function and its coefficients. The canonical technique involves the computation of Eigen values and Eigen vectors as well as the canonical correlation coefficients. The computed Eigen value was 2.492 and the canonical correlation coefficient was as high as 0.845 . These parameters were tested for their significance using Wilk's lambda (1) and chi-square and they were found to be significant at $1.00 \%$ (Table 3.0).

The discriminating variables were correlated with the standardized canonical discriminant function, and were consequently re-arranged in their order of importance based on the absolute size of the coefficients (Table 4.0). The standardized canonical discriminant function coefficients are given in equation (15).

Table 3.0: Eigen values and Wilk's lambda $(\lambda)$

\begin{tabular}{ccccccc}
\hline $\begin{array}{c}\text { Test of } \\
\text { functions }\end{array}$ & $\begin{array}{c}\text { Eigen } \\
\text { value }\end{array}$ & $\begin{array}{c}\text { Canonical } \\
\text { correlation }\end{array}$ & $\begin{array}{c}\text { Wilk's } \\
\text { lambda }\end{array}$ & $\begin{array}{c}\text { Chi- } \\
\text { square }\end{array}$ & $\begin{array}{c}\text { Degree of } \\
\text { freedom }\end{array}$ & Sig. \\
\hline Function 1 & 2.492 & .845 & .286 & 117.551 & 8 & .000 \\
\hline
\end{tabular}

$$
\begin{aligned}
\mathrm{L}= & \mathrm{X}_{1}(.466)+\mathrm{X}_{2}(.058)+\mathrm{X}_{3}(-.036)+\mathrm{X}_{4}(-.029)+\mathrm{X}_{5}(0.017) \\
& +\mathrm{X}_{6}(.843)+\mathrm{X}_{7}(-.040)+\mathrm{X}_{8}(-.122)
\end{aligned}
$$

156 Journal of Science and Technology, Volume 27 no. 2, August, 2007 
Table 4.0: The structure matrix

\begin{tabular}{cc}
\hline Discriminating variable & Function 1 \\
$\mathrm{X}_{6}$ & .882 \\
$\mathrm{X}_{1}$ & .491 \\
$\mathrm{X}_{8}$ & -.152 \\
$\mathrm{X}_{3}$ & -.103 \\
$\mathrm{X}_{4}$ & -.083 \\
$\mathrm{X}_{7}$ & -.034 \\
$\mathrm{X}_{2}$ & .021 \\
$\mathrm{X}_{5}$ & .016 \\
\hline
\end{tabular}

The unstandardized canonical discriminant function coefficients are given, with the intercept value on the discriminant hyper plane, as:

$$
\begin{aligned}
\ell= & -3.652+\mathrm{X}_{1}(1.197)+\mathrm{X}_{2}(.089)+\mathrm{X}_{3} \\
& (-.088)+\mathrm{X}_{4}(-.070)+\mathrm{X}_{5}(.039)+\mathrm{X}_{6}(.247) \\
& +\mathrm{X}_{7}(-.166)+\mathrm{X}_{8}(-.249)
\end{aligned}
$$

The second approach to the discriminant analysis was the computation of Fisher's linear discriminant function coefficients for the classification of female drivers into their proper mode-choice groups. The coefficients for the two groups i.e public and private modes are shown in Table 5.0. Fisher's linear discriminant functions coeffi-

Table 5.0: Fisher's classification function coefficients

\begin{tabular}{ccc}
\hline $\begin{array}{c}\text { Discriminating } \\
\text { variables }\end{array}$ & $\begin{array}{c}\text { Private } \\
\text { mode }\end{array}$ & $\begin{array}{c}\text { Public } \\
\text { mode }\end{array}$ \\
\hline $\mathrm{X}_{1}$ & $4.977^{*}$ & 1.209 \\
$\mathrm{X}_{2}$ & $3.594^{*}$ & 3.314 \\
$\mathrm{X}_{3}$ & 5.220 & $5.498^{*}$ \\
$\mathrm{X}_{4}$ & 2.624 & $2.846^{*}$ \\
$\mathrm{X}_{5}$ & $3.996^{*}$ & 3.873 \\
$\mathrm{X}_{6}$ & $1.529^{*}$ & .752 \\
$\mathrm{X}_{7}$ & 15.797 & $16.320^{*}$ \\
$\mathrm{X}_{8}$ & 2.205 & $2.988^{*}$ \\
Constant & -30.779 & -19.875 \\
\hline
\end{tabular}

Nota bene: Asterisked (*) figures have higher values cients offer explanation on the effect of each of the variables on the mode-choice behaviour of women in the study area. Variable $\mathrm{X}_{1}$ (Access to private car) was heavily loaded on the private mode, which means that those women who have unrestricted access to private cars at home will persistently prefer the private car mode to public transport.

Another variable that was heavily loaded on the private mode is variable $\mathrm{X}_{2}$ (Number of cars in the family). This portends that female drivers who have many private cars at home will definitely find it difficult to abandon them and patronize public transport modes. The coefficients further revealed that those women who perceive car ownership as a status symbol (Variable $\mathrm{X}_{5}$ ) would cling to the use of private cars. Travel time from home to work (variable $\mathrm{X}_{6}$ ) was also loaded heavily on the private car function and this means that those women who spend longer time commuting from home to work and vice versa will ineluctably prefer to use their private cars most of the time.

On the other hand, perception of car use as agent of environmental pollution (variable $\mathrm{X}_{3}$ ) was loaded heavily on the public transport function, and this means that those female drivers who have this type of awareness or perception will definitely be willing to discard their private cars for public transport modes. Furthermore, perception of car use as a contributory factor to traffic congestion was loaded heavily on the public transport function. This is indicative of the fact that those who recognize car use as a factor responsible for traffic congestion are more likely to discard their private cars for public transport mode. The other variables that were heavily loaded on public transport function are the level of education of female drivers and their level of perception of public service in Akure. The explanation in this case is that those female drivers who are educated and who also feel that the public transport service in Akure is satisfactory, are more likely to discard their private cars for public transport in Akure. 
The summary statistics of the classification of the 100 female drivers into their predicted modechoice groups is presented in Table 6.0. The empirical data showed that for private mode group, 56 female drivers were counted, but the model predicted 53 for that group. The three respondents who said they would continue to use private cars were therefore re-assigned to the public transport mode. On the other hand, 44 female commuters claimed that they would drop their private cars for the public transport mode, while the model predicted 47 . The overall percent of original grouped cases correctly classified is as high as $95 \%$, thus attesting to the efficacy of the predictive prowess of the model (Table 6.0). Interestingly, this percentage of correctly classified cases synchronizes perfectly with the predictions made by the binary logit model.

Table 6.0: Discriminant model classification result

\begin{tabular}{|c|c|c|c|}
\hline \multirow{2}{*}{$\begin{array}{l}\text { Original } \\
\text { count }\end{array}$} & \multicolumn{2}{|c|}{$\begin{array}{c}\text { Predicted group } \\
\text { membership }\end{array}$} & \multirow{2}{*}{ Total } \\
\hline & $\begin{array}{c}\text { Private } \\
\text { mode }\end{array}$ & $\begin{array}{l}\text { Public } \\
\text { mode }\end{array}$ & \\
\hline Private mode & 52 & 4 & 56 \\
\hline Public mode & 1 & 43 & 44 \\
\hline Total & 53 & 47 & 100 \\
\hline
\end{tabular}

$95 \%$ of original grouped cases correctly classified

\section{Policy Issues and Conclusion}

One of the veritable ways of encouraging female commuters to accord patronage to public transport is to intimate them with the connection between environmental pollution and car use. There is need for an enlightenment programme to be put in place to educate the populace on the relationship between global warming and emission of greenhouse gases from the exhaust of motorcars. The deleterious effects of car use on the ambient air, and its contributory role in creating a global greenhouse should be highlighted to car users.
As a corollary to this, there is need for a similar enlightenment programme to highlight the fact that too many cars on the roads contribute immensely to acute traffic congestion and the concomitant traffic management crisis in the cities. It is also essential to empower female drivers academically to increase their awareness on the interconnection and correlation between traffic congestion and environmental pollution. It is axiomatic to state that all of this is predicated on an efficient, convenient and standard public transport service provision in the town. There is therefore no gain saying the fact that the major motivating factor that could allure or entice female car-owners to the public transport sector is an efficient public transport service.

In order to encourage female car owners to discard their cars for public transport in Akure, the level of public transport service delivery must be enhanced and made attractive enough to lure people from their cars. The mass transit buses must be in good conditions. They must also be clean, comfortable, and regular in their schedule and must have a city-wide coverage to make it attractive to car owners. This is not yet the situation in Akure town. If the public transport sector is satisfactory, people who cannot abandon their cars completely should, at least, be able to ration the use of their cars. There should be a policy to discourage private cars from using some designated roads that carry heavy traffic during the rush hours.

Conversely, there are certain policy issues that must be pursued in order to discourage female car owners from using their private cars. The study revealed that those that stuck stubbornly to private car use are those who have unrestricted access to private cars. This study advocates a policy instrument that will restrict the use (but not ownership) of private cars on urban roads. One veritable strategy that could be employed by the government as a policy instrument to achieve car reduction on the road is the introduction of taxes and charges. The tax in question could be

158 Journal of Science and Technology, Volume 27 no. 2, August, 2007 
in form of toll tax. The proceeds from such taxes or toll could then be used to provide standard mass transit facilities. This practice is in consonance with the famous Robin Hood Principle. The major tenet of the Robin Hood Principle is to tax car users heavily and with the booty, subsidize mass transit delivery and make it alluring, captivating and enticing to car owners.

In conclusion, the issue of mode-choice behaviour of car owners is a topical subject. This is partly so because it is seemingly ludicrous that a car owner would abandon his or her car and travel by a public mode. The utilities of a private car are copious and one would not expect a car owner to easily park his or her car and use a public transport, especially in a situation where the level of service rendered by public transport is sub-optimal. Some of the utilities of a private car include comfort, convenience, flexibility and the fact that it is seen as a symbol of prestige. In developed countries where public transport is well organized and proficient, car owners find it expedient to park their cars at home and commute by public transport to their work places. This is an example that is worthy of emulation by car owners in Nigerian cities.

\section{REFERENCES}

Arosanyin, G.T (2000). The Economic Cost of Road Accidents Victims in Nigeria. Indian Journal of Transport Management. Vol. 24 No. 6, pp. $441-449$.

Asensio, J. (2002). Transport Mode Choice by Commuters to Barcelona's CBD. Urban Studies, Vol. 39 No. 10, pp. 1881 - 1895.

Atash, F. (1994). Redesigning Suburbia for Walking and Transit: Emerging Concepts, Journal of Urban Planning and Development, 120 , pp. $48-57$.

Bailey, K.D. (1982). Methods of Social Research $\left(2^{\text {nd }}\right.$ Edn.) (New York: The Free Press).

Cervero, C. and Radisch, C. (1996). Travel Choice in Pedestrain Versus Automobile
Oriented Neighbourhoods, Transport Policy, Vol. 3 No. 3 pp. $127-141$.

Davidson, D.J. and Freudenburg, W.R. (1996). Gender and Environmental Risk Concerns: A Review and Analysis of Available Research. Environment and Behaviour, 28 pp. $302-339$.

Eskeland, G.S (1994). A Presumptive Pigovian Tax: Complementing Regulation to Mimic an Emissions Fee. The World Bank Economic Review, Vol. 8, No. 3, pp. 373-394.

Fadare, S.O. and Morenikeji, W. (2001). GenderBias in Intra-Urban Trip Pattern in Niger State, Nigeria. International Journal of Transportation Studies. Vol. 1 No. 1 pp.7385.

Flade, A. (1989). Mobility Requirements of Women. Raumplanung, 46/47 pp.179 - 184.

Guiliano, G. (1979). Public Transportation and the Travel Needs of Women. Traffic Quarterly, 33, pp. $607-616$.

Hanson, A. and Hanson, P. (1980). Gender and Urban Activity Pattern in Upsalla, Sweden. Geographical Review, 70, pp. 291 - 299.

Hughes, P. (1993). Personal Transport and the Green House Effect (London: Earthscan).

Kaiser, F. G. (1998). A General Measure of Ecological Behaviour, Journal of Applied Social Psychology, 28, pp. $395-422$.

Kanafani, A. (1983). Transportation Demand Analysis (New York: McGraw-Hill).

Law, R. (1999) Beyond 'Women and Transport': Towards New Geographies of Gender and Daily Mobility. Progress in Human Geography, Vol. 23, No. 4, pp. 567 - 588.

Maddison, D; Pearce, D. and Johansson, D. (1996). Blueprint 5: The True Cost of Road Transport (London: Earthscan).

Matalon, B. (1992) Mobility with regards to Social Groups and Attitudes. Transportation and Roads Research Laboratory Reports, 689 , pp. 1330151. 
Matthies, E.; Kuhn, S; and Klockner, C.A (2002). Travel Mode Choice of Women: The Result of Limitation, Ecological Norm, or Weak Habit? Environment and Behaviour, Vol. 34 No. 2 pp. 163 - 177.

Ouellette, J. A. and Wood, W. (1998). Habit and Intention in Everyday Life: The Multiple Processes by which Past Behaviour Predicts Future Behaviour. Psychological Bulletin, 124(1), pp. $54-74$

Papacostas, C.S (1987). Fundamentals of Transportation Engineering (New Jersey: Prentice-Hall, Inc.)

Peirson, J.; Skinner, I. and Vickerman, R. (1996). Estimating the External Costs of U.K. Passenger Transport: The First Steps Towards an Efficient Transport Market, Environment and Planning A, 27, pp. 1977 - 1993.

Potter, S. and Hughes, P. (1990). Vital Travel Statistics (London: Transport 2000).

Rosenbloom, S. (1978). Editorial: The Need for Study of Women's Travel Issues. Transportation, 7 , pp. $347-350$.
Tolley, R.S. (Ed.) (1977). The Greening of Urban Transport: Planning for Walking and Cycling in Western Cities, $2^{\text {nd }}$ edn. (Chichester: Wiley).

Ullrich, O. (1990) The Pedestrain Town as an Environmentally Tolerable Alternative to Motorised Travel, in; R. S. Tolley (Ed.). The Greening of Urban Transport: Planning for Walking and Cycling in Western Cities, pp. 97 - 109 (London: Belhaven Press).

Verplanken, B.; Aarts, H; and Van Knippenberg, C. (1994). Attitude versus General Habit: Antecedents of Travel Mode Choice. Journal of Applied Social Psychology, 24, pp. $285-300$.

Whitelegg, J. (1993) Transport for a Sustainable Future: The Case for Europe (London: Belhaven Press).

Wrigley, N. (1981). Categorical Data Analysis in Quantitative Geography (London: Routledge and Kegan Paul). 